\title{
BACKSCATTERING MEASUREMENTS OF P+ IMPLANTED GaAs CRYSTALS
}

\author{
is. TASHLYKOV \\ Irstitute of Applied Phy'sics, Beloroussia State University, 220080 Minsk. USSR
}

Implantation of phosphorus and aluminium ions into GaAs is important in the investigation uf the transtormation processes which can take place during ion implantation and in the fabrication of heterojunctions.

In this paper profiles of phosphorus, implanted into GaAs at different energies, temperatures, doses and dose rates and depth ' Jributions of damage are discussed. For room temperature implantations, the range of the defect peak exceeds $\bar{R}_{\text {p.theor }}$ by

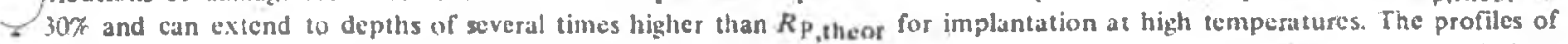
in:: Junted phosphorus are characterized by a complicated distribition. Using the RBS technique the estinated depth of phosp: rus profiles ranges up to hundreds of nanometers.

discussion of the recently observed effect of high ion beam current density on damage and the distribution of implanted

. is presented.

\section{1. troduction}

se implantation of GaAs with $\mathrm{P}^{+}$and $\mathrm{Al}^{+}$is interes: 10 study from the point of view of daniage for. m. $n$, appearance of new phases (like $\mathrm{GaAs}_{1-X} \mathrm{P}_{X}$ an $A l_{X} \mathrm{Ga}_{1-X} \mathrm{As}$ ) and structural transformations yo ring during ion implantation because these are in I $_{\text {rtant }}$ in the fabrication of heterojunctions.

(fom studies performed by optical techniques it is kn wn that room temperature $\mathrm{P}^{*}$ implantation into Gigls with a subsequent high-temperature anneal or $p^{*}$ implantation into warmed-up GaAs crystals results 7 the formation of ternary compounds, such as $C_{2} \mathrm{As}_{1}-X^{P_{X}}$, which are capable of luminescence in the visible range of the spectrum $[1-3]$

Our experimental studies have also shown that implantation of $\mathrm{P}^{+}$into $\mathrm{GaAs}$ is characterized by a number of peculiarities in the distribution and behav. iour of the defects and in the profiles of the implanted conponent when the fluence, ion current density and temperature are varied.

In this report some new results about damage and P.atom profiles in $\mathrm{P}^{*}$ implanted GaAs are given. A discussion of the recently observed effect of high ion beam current density on damage and the distribution of imnlanted atoms is presented.

\section{Experimental details}

Crystals of GaAs having (111) orientation were hiplanted with ${ }^{31} \mathrm{P}^{4}$ at energies of 30,40 and $60 \mathrm{keV}$,
Implant doses ranged from $3 \times 10^{15} ? \times 10^{17}$ ions $\mathrm{cm}^{-2}$. The crystal temperature during the bombard. ment was cluse to $T_{\text {room }} 150.300,350,400$ and $450^{\circ} \mathrm{C}$. The ion current densities for different sets uf sumples were in the muthib 5-7. 10 15. $30-$ $40 \mathrm{mkA} \mathrm{cm}^{-2}$.

The crystals were examined in the roun senipe-a. ture chumber of the F. Schiller University (fiDk) $2 \mathrm{MeV}$ Van de Graaff accelerator, using backseattering of $1.4 \mathrm{MeV}{ }^{4} \mathrm{He}^{*}$. The energies of the backscattered ions were measured using a surface barrier detector at a scattering angle of $160^{\circ}$, together with the usual electronic means jor pulse height analysis. The energy resolution was $15 \mathrm{keV}$ full width at half-maxinium. In converting to the depth scale the rabulated values of the stopping cross sections in ref. (4) were used. The depth profiles were extracted after applying the dechannelling correction obtained using in iterative technique based upon the plural scattering approximation [5]. The effect of the changing atom concentration in the surface layers of the implanted crystals was taken into account.

\section{Experimental results and discussion}

Figure 1 shows typical spectra for backscattered He ions from the original (curves 1 and 2) and implanted (curves 3 to 6) cyrstals. Room temperature implantation leads to the formation of a damaged layer whose magnitude exceeds (by 20 to $30 \%$ ) the theoretically estimated projected range of $\mathrm{P}^{+}$in $\mathrm{GaAs}$ 


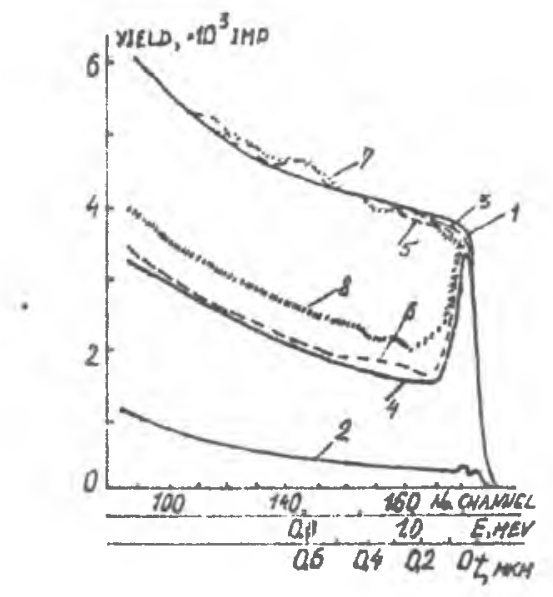

Fig. 1. Backscattering spectra of GaAs using $1.4 \mathrm{MeV} \mathrm{He}^{*}$ for random - 1, and (111)-channclling - 2; before implantation and after $3 \times 10^{15}$ jons $\mathrm{cm}^{-2}, 3$ and $4 ; 3.2 \times 10^{16}$ ions $\mathrm{cm}^{-2}-5$ and $6 ; 8 \times 10^{16}$ ions $\mathrm{cm}^{-2}-7$ and $8 . \mathrm{Ep}_{\mathrm{p}^{+}}=$ $60 \mathrm{keV}$.

[6]. The axial spectra exhibit defect "tails" extending to depths of some hundreds of nanometers. With increasing fluence (over the interval investigated) a slight increase in the defect concentration occurs due to a depth extension of the damaged layer.

The damage profiles in $\mathrm{P}^{*}$ implanted at $T_{\text {room }}$ GaAs crystals are shown in fig. 2 (curves 1 and 2 ). The amorphous layers begin at the very surface, their thickness is estimated to be $30-35 \mathrm{~nm}$ and increases with dose.

The distribution of the phosphorus implanted under such conditions is characterized by two main peaks, fig. 3 . Its range is estimated to be some hundreds of nanometers, that is several times higher than $\boldsymbol{R}_{\text {p,theor }}$. Table 1 shows the theoretical estimates of

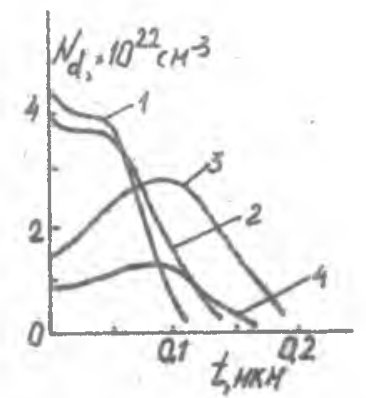

Fig. 2. Defect distribution profiles in $\mathrm{P}^{\star}$ ion implanted GaAs. $T_{\text {impl }}=20^{\circ} \mathrm{C}, E=30 \mathrm{keV}, D=1.6 \times 10^{16}$ ions $\mathrm{cm}^{-2}-1$; $D=7 \times 10^{16}$ ions $\mathrm{cm}^{-2}-2 ; T_{\text {impl }}=300^{\circ} \mathrm{C}, D=8.2 \times$ $10^{26}$ ions $\mathrm{cm}^{-2}-3 ; T_{\text {impl }}=350^{\circ} \mathrm{C}, D=3.3 \times 10^{16}$ jons $\mathrm{cm}^{-2}-4$.
Table 1

Theoretically estimated projected range of $\mathrm{P}^{+}$ion in $\mathrm{GaA}$. $\left(K_{p}\right)$, straggling $\left(\Delta \bar{R}_{p}\right)$, and the projected range in the axia (111) channelling $\left(R_{\max }\right)$

\begin{tabular}{lllll}
\hline $\begin{array}{l}E \\
(\mathrm{keV})\end{array}$ & 30 & 30 & 60 & Ref. \\
\hline$R_{\mathrm{p}} \mathrm{nm}$ & 30.0 & 39.7 & 59.2 & {$[6]$} \\
& 34.8 & 32.4 & 47.6 & {$[7]$} \\
$\Delta \bar{R}_{\mathrm{p}} \mathrm{nm}$ & 23.5 & 30.5 & 42.9 & {$[6]$} \\
& 15.7 & 19.6 & 27.1 & {$[7]$} \\
$R_{\max }(111), \mathrm{mkm}$ & 2.76 & 3.19 & 3.90 & {$[8]$} \\
\hline
\end{tabular}

$\bar{R}_{\mathrm{p}}$ and $\Delta R_{\mathrm{p}}$ for comparison with the experimental data.

The increase with dose of the phosphorus con. centration in the first peak is shown in fig. 3 . The depth distribution of phosphorus was almost indeps:3dent of the $\mathrm{P}^{+}$energy (at $j<30 \mathrm{mkA} \mathrm{cm}^{-2}$ ).

With increased implantation temperatures $\left(T_{\text {impi }} \geqslant\right.$ $150^{\circ} \mathrm{C}$ ) there is no amorphization of $\mathrm{Ga} \wedge \mathrm{s}$ cryst is during $P^{+}$implantation up to fluences of $7 \times 10^{17} \mathrm{ir}$ is $\mathrm{cm}^{-2}$. The depth at which the peak of the defect $\mathrm{c}: \mathrm{u} \cdot$ centration is observed is several times greater $t$ in that for the room temperature implantation, $\mathrm{fi}_{l} 2$ (curves 3 and 4). With increasing fluence the num er of the defects grows due both to a slight increas in their concentrations and to the extension of he defect peak towards the surface.

The axial spectra of the crystal bombarder at higher temperatures exhibit defect "tails", । ith depths approaching some hundreds of nanome ers

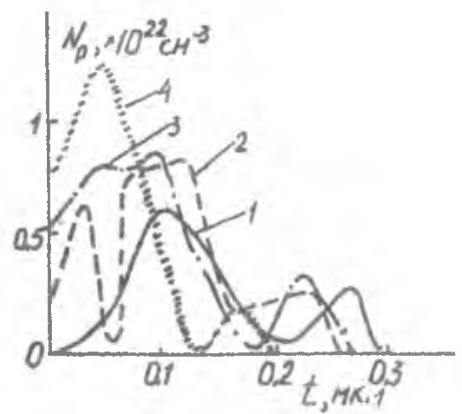

Fig. 3. Distribution profiles of phosphorus implanted into GaAs. $T_{\text {impl }}=20^{\circ} \mathrm{C}, E=30 \mathrm{keV}, j=5-7 \mathrm{mkA} \mathrm{cm}^{-2}, D=$ $1.6 \times 10^{16}$ ions $\mathrm{cm}^{-2}-1 ; D=7 \times 10^{16}$ jons $\mathrm{cm}^{-2}-2 ; E^{2}$ $60 \mathrm{keV}, j=5-10 \mathrm{mkA} \mathrm{cm} \mathrm{cm}^{-2}, D=8 \times 10^{16}$ jons $\mathrm{cm}^{-2}-3$. $E=40 \mathrm{keV}, I=30-40 \mathrm{mkA} \mathrm{cm}^{-2}, D=4 \times 10^{17}$ ions $\mathrm{cm}^{-2}$ -4 . 


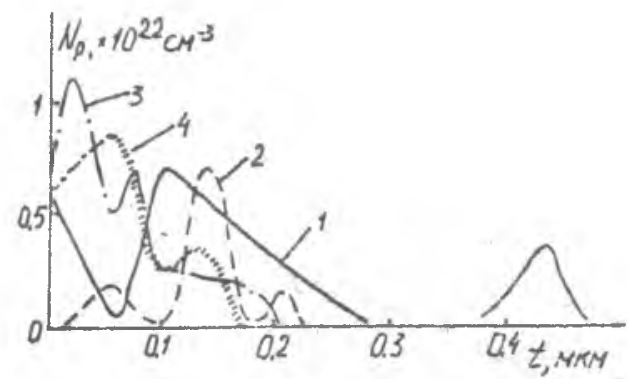

I ig. 4. Distributions profiles of phosphurus implanted into (..iAs. $E=30 \mathrm{keV}, T_{\text {impl }}=300^{\circ} \mathrm{C}, j=5-7 \mathrm{mkA} \mathrm{cm}{ }^{-2}, D=$ $8.2 \times 10^{16} \mathrm{~cm}^{-2}-1 ; T_{i m p l}=400^{\circ} \mathrm{C}, D=2 \times 10^{16} \mathrm{~cm}^{-2}-$ $\therefore T_{\text {impl }}=450^{\circ} \mathrm{C}, j=10-15 \mathrm{mkA} \mathrm{cm}{ }^{-2}, D=2.7 \times$ I.1 $7 \mathrm{~cm}^{-2}-3 ; E=60 \mathrm{keV}, T_{\mathrm{impl}}=450^{\circ} \mathrm{C}, D=4 \times$ 1. $17 \mathrm{~cm}^{-2}-4$.

1 ich is somewhat higher than that for the room $\therefore$ perature implantation).

ihe distribution protiles of the phosphorus i. tunted at high temperature are also characterized 6 monerus pedis. moreover, the range of phos.

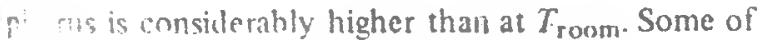
1: Gosphorus protiles in the GaAs crystals implanted a igh temperature are presented in fig. 4. The numb. und the depth of the phosphorus peaks increases $W_{i}$ : the dose of ions and decreases with the tempera. Iu: of implantation.

1) $n$ increasing the current density of the ion beam oi $30-40 \mathrm{mkA} \mathrm{cm}^{-2}$ the profiles for the defecrs and implanted phosphorus acquire characteristics different from those discussed above. For illustration, figs. 5 and 6 present the spatial distributions of the defiects and the phosphorus when phosphorus was fiplanted into $\mathrm{GaAs}$ at different temperatures.

The phosphorus profiles at each implantation temperature exhibit a well defined peak which lies almust at same depth as that predicted theoretically [6]. hough straggling is somehow larger. These

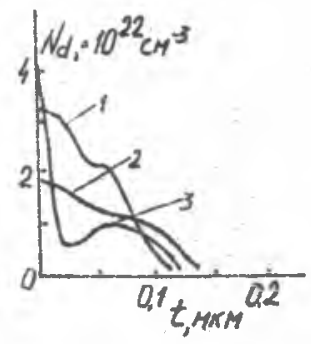

Fy. 5. Defect distribution proflles in $P^{*}$ ion implanted GaAs. $E-40 \mathrm{keV}, j=30-40 \mathrm{mkA} \mathrm{cm}^{-2}, D=4 \times 10^{17}$ ions $\mathrm{cm}^{-2}$, $T_{\text {impl }}=20^{\circ} \mathrm{C}-1 ; 150^{\circ} \mathrm{C}-2 ; 400-450^{\circ} \mathrm{C}-3$.

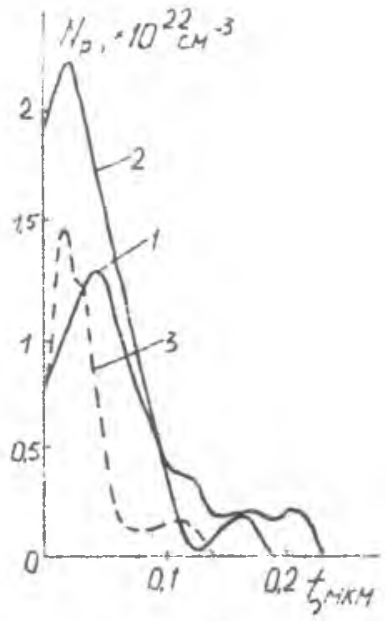

Fig. 6. Distribution profiles of phosphieras implanted into GaAs with a high current density ion beum. $E=40 \mathrm{keV}, j=$

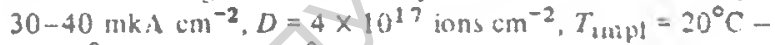
$1: 150^{\circ} \mathrm{C}-2 ; 400-450^{\circ} \mathrm{C}-3$.

results correlate well with the profiles in ref. [9], obtained by studying the distribution of radioactive phosphorus using the technique of successively

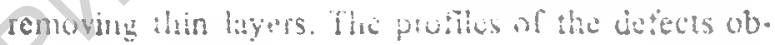
lained by the backscattering tohnicite tig. 51 were found to be at the depth corresponding is the range of the implanted phuspinorus.

The complex character of the variation in the phosphorus spatial distribution within GaAs undoubtedly indicates a competition between two counteracting proccsses: the synthesis reaction rate of a chemical crmpound like $\mathrm{GaAs}_{1-\lambda} \mathrm{P}_{X}$ and the dissociation rate of the chemical bonds formed. The authors of ref. [10] in studying the synthesis of silicon nitride and silicon carbide by means of $\mathrm{N}^{*}$ and $\mathrm{C}^{*}$ ion iniplantation into Si have shown the iriportance of accounting for the basic processes affecting structural transiormations in implanted crystals in order to better understand experimental results.

\section{Conclusions}

Some of the main experimental results which were obtained during the present investigation can be summarized as follows:

for room temperature implantations, the range of the defect peak exceeds the phosphorus ion projected range in non-oriented $\mathrm{GaAs}$ by $20-30 \%$.

the damage profiles extend to depths of $n R_{\mathrm{p}}(n$ can range from 1 to 5 ) for implantation at high temperatures. 
Defect "tails" can exist in the crystals extending to depths of some hundreds of nanometers for implan. tation both at room and at high temperatures.

The profiles of implanted phosphorus are charac. terized by a complicated distribution and the number of peaks increase with dose and increasing implantation temperature. Using the RBS technique the estimated depths of phosphorus profiles range up to hundreds of nanometers.

The use of high $\mathrm{P}^{+}$ion beam current density $(J>$ $30 \mathrm{mkA} \mathrm{cm}^{-2}$ ) is an effective technique for reducing the level of damage and depth of damage and to achieve an implanted phosphorus range close to that predicted by LSS theory.

\section{References}

[1] R.G. Hunsperger and O.J. Marsh, J. Appl. Phys. Lett. 19 (1971) 327 .
[2] K. Umo, Erecutoronicusu, Elektron. Mag. 15 (197C 1140.

[3] I.M. Belyi, G.A. Gumanskii, V.I. Karas, V.M. Lomakı I.S. Tashlykov and V.S. Tishkov, Fis. tekhn. Polup. (1975) 2024.

[4] J.F. Ziegler and W.K. Chu, Thin Solid Films 19 (197 281.

[5] E. Kell, B. Zeitler and W.Z. Zinn, Z. Naturforsch. 1 (1960) 1031.

[6] M.A. Kumakhov, V.A. Muravlev, E.G. Aver'yanov, V. Simonov and L.G. Khavkin, St. Dep. Vsesoyusn. In Nauch. Tekhn. Inform., No. 700-75 (1975).

[7] D.K. Brice, SC-RR-71, No. 0599.

[8] F.F. Komarov and M.A. Kumakhov, Phys. Stat. (b)58 (1973) 389.

[9] W. Zuk, D. Bazyluk and E. Tarnowska, Foia Soc., : Lubl., Mat. fys. Chem. 2 (1976) 237.

[10] B.B. Glasman, L.V. Lesheiko, E.V. Lyubopytova L.S. Smirnov, Tesisy dokladov Vsesoyusnoi konferer "Radiat sionnye effekty $v$ tverdych telakh", Ashkha! 1977. 